\title{
Role of phytotherapy associated with antibiotic prophylaxis in female patients with recurrent urinary tract infections
}

\author{
Emanuela Frumenzio, Daniele Maglia, Eleonora Salvini, Silvia Giovannozzi, \\ Manuel Di Biase, Vittorio Bini, Elisabetta Costantini \\ Clinica Urologica e Andrologica di Perugia, Università degli Studi di Perugia, Italy
}

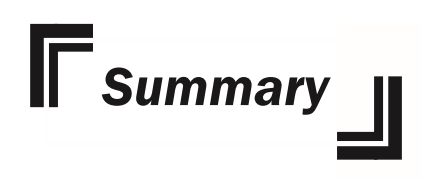

Objective: Aim of this study is to evaluate the efficacy of a phytotherapic which includes Solidago, Orthosiphon and Birch extract (Cistimev ${ }^{\circledR}$ ) in association with antibiotic prophylaxis in female patients affected by recurrent urinary tract infections (UTIr).

Materials and methods: Patients affected by UTIr older than 18 years started a 3-months antibiotic prophylaxis (Prulifloxacin $600 \mathrm{mg}, 1 \mathrm{cps} /$ week or Phosphomicyn 1 cachet/week) according to antibiogram after urine culture. The patients were divided in 2 groups: Group A: antibiotic prophylaxis plus phytotherapy (1 cps/die for 3 months) and Group B: antibiotic prophylaxis alone.

Results: 164 consecutive patients were studied: 107 were included in group A (mean age $59 \pm 17.3$ years) and 57 (mean age $61 \pm 15.7$ ) in group B. During the treatment period the relapse frequencies between the two groups were not significantly different $(p=0.854): 12 / 107(11.21 \%)$ patients interrupted the treatment for UTIr in group A and 6/57 (10.52\%) in group B. In the long term follow-up the relapse UTI risk was significant different in the two groups with a relapse risk 2.5 greater in group $B$ than in group $A(p<0.0001)$.

Conclusion: Our study demonstrated that in female patients affected by recurrent UTI, the association between antibiotic prophylaxis and of a phytotherapic which includes Solidago, Orthosiphon and Birch extract reduced the number of UTI in the 12 months following the end of prophylaxis and obtained a longer relapsing time, greatly improving the quality of life of the patients.

KEY WORDS: Recurrent urinary infection; Phytotherapy; Antibiotc prophylaxis.

\section{INTRODUCTION}

The bacterial adhesiveness to the bladder walls is important virulence factor in the pathogenesis of urinary tract infections. The development of a biofilm that prevents bacterial adhesion plays an important role in prophylaxis of recurrent urinary tract infections (UTIr). Aim of this study is to evaluate the efficacy of a phytotherapic which includes Solidago, Orthosiphon and Birch extract $\left(\right.$ Cistimev $\left.^{\circledR}\right)$ in association with the antibiotic prophylaxis in female patients affected by (UTIr)

\section{Materials AND MEthods}

All the female patients affected by UTIr who referred to our urogynaecological unit between September 2010 and
January 2012 were included in a retrospective study comparing antibiotic prophylaxis alone or combined with Solidago, Birch e Ortosiphon (Cistimev ${ }^{\circledR}$ ).

UTIr was defined as at least three episodes of uncomplicated infection documented by urine culture (EAU guidelines) (1)

Paatients affected by UTIr older than 18 years started a 3-months antibiotic prophylaxis (Prulifloxacin $600 \mathrm{mg}$, 1 cps/week or Phosphomicyn 1 cachet /week) according to antibiogram after urine culture. The patients were divided in 2 groups: Group A: antibiotic prophylaxis plus phytotherapy ( 1 cps/die for 3 months) and Group B: antibiotic prophylaxis alone.

Exclusion criteria were patients with less than three 
Table 1.

\begin{tabular}{|c|c|c|c|c|c|}
\hline \multirow[b]{2}{*}{ Antibiotic prophylaxis } & \multicolumn{2}{|c|}{ Group A } & \multicolumn{2}{|c|}{ Group B } & \multirow{2}{*}{$\begin{array}{c}\mathbf{p} \\
<0.540\end{array}$} \\
\hline & $\begin{array}{l}55 / 107(51.4 \%) \text { pts } \\
\text { Prulifloxacin }\end{array}$ & $\begin{array}{c}\text { 52/107(48.6\%) pts } \\
\text { Phosphomicyn }\end{array}$ & $\begin{array}{c}29 / 57(50.9 \%) \text { pts } \\
\text { Prulifloxacin }\end{array}$ & $\begin{array}{c}\text { 28/57 (49.1\%) pts } \\
\text { Phosphomicyn }\end{array}$ & \\
\hline Sexual activity & $\begin{array}{c}62 / 107(57.9 \%) \text { pts } \\
\text { sexual activity }\end{array}$ & $\begin{array}{c}45(42.1 \%) \text { pts } \\
\text { no sexual activity }\end{array}$ & $\begin{array}{c}\text { 30/57 }(52.6 \%) \text { pts } \\
\text { sexual activity }\end{array}$ & $\begin{array}{c}27 / 57(47.4 \%) \text { pts } \\
\text { no sexual activity }\end{array}$ & $<0.312$ \\
\hline Menopause & $\begin{array}{c}\text { 72/107(67.3\%) pts } \\
\text { menopause }\end{array}$ & $\begin{array}{c}\text { 35/107 }(32.7 \%) \text { pts } \\
\text { no menopause }\end{array}$ & $\begin{array}{l}\text { 44/57(77.2\%) pts } \\
\text { menopause }\end{array}$ & $\begin{array}{c}13 / 57(22.8 \%) \text { pts } \\
\text { no menopause }\end{array}$ & $<0.125$ \\
\hline Incontinence & $\begin{array}{l}\text { 56/107(52.3\%) pts } \\
\text { incontinence }\end{array}$ & $\begin{array}{c}51 / 107 \text { (47.7\%) pts } \\
\text { no incontinence }\end{array}$ & $\begin{array}{c}\text { 36/57 (63.2\%) pts } \\
\text { incontinence }\end{array}$ & $\begin{array}{c}21 / 57 \text { (36.8\%) pts } \\
\text { no incontinence }\end{array}$ & $<0.122$ \\
\hline
\end{tabular}

uncomplicated UTIs in the previous year; significant (> 50 $\mathrm{ml}$ ) residual urine; pregnancy; intolerance or allergy to drug compounds, Pelvic Organ Prolapse more than stage II (POP-q quantification).

All patients were assessed by history, clinical examination, urine culture, uroflowmetry parameters and postvoid residual volume evaluation.

The patients in both groups were followed-up with urine analysis and urine culture during the treatment every month and after the end of therapy at 3, 6 and 12 months. Primary outcome was the efficacy in preventing infection recurrences during the treatments and the evaluation of UTI relapse risk in the year after the end of therapy in both groups.

Statistical analysis: chi2 test was used for comparisons of categorical variables; Kaplan-Meier estimation with logrank test was applied to compare the relapse-free survival time in both groups.
The survival curves (Figure 1) demonstrated that 25\% of patients that underwent the antibiotic prophylaxis plus Phytotherapy had no recurrence at 1 year, while all the patients in group B had at least one recurrence within 1 year.

It is also evident that the time to recurrence is always longer in group $\mathrm{A}$, in fact the mean survival time was 10.4 months in group A and 3.6 months in group B (log-rank test $\mathrm{p}<0.0001$ )

\section{Discussion}

A major problem today in public health economy is the increase in multi-resistant micro-organisms in patients with recurrent cystitis.

New therapeutic and behavioural strategies are needed to prevent recurrences. Using drugs based on natural substances which are free of side effects may have a place in the armentarium for these very hard to treat patients.

\section{RESULTS}

164 consecutive patients were studied: 107 were included in group A (mean age $59 \pm 17.3$ years) and 57 (mean age $61 \pm 15.7$ ) in group $B$. Both groups were equivalent: there were no statistically significant difference, as regards the type of antibiotic chosen (Prulifloxacin or Phosphomicyn), menopausal status, sexual activity, urinary incontinence and residual urine (Table 1 ). No patients reported side effects in both groups.

During the treatment the relapse frequencies between the two groups were not significantly different ( $\mathrm{p}=$ 0.854): 12/107 (11.21\%) patients interrupted the treatment for UTIr in group A and 6/57 (10.52\%) in group $\mathrm{B}$. In the long term follow-up the relapse UTI risk was significant different in the two groups with a relapse risk 2.5 greater in group $\mathrm{B}$ than in group $\mathrm{A}(\mathrm{p}<0.0001)$.

Figure 1.

Kaplan-Meier survival analysis.

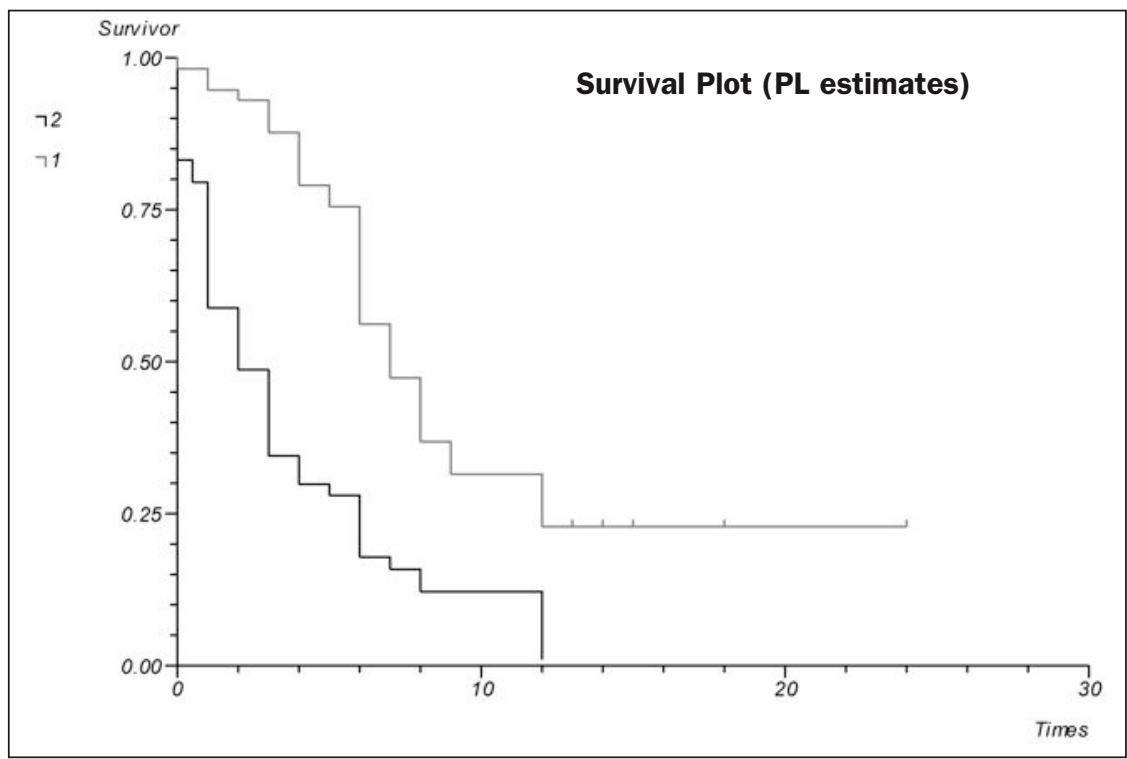


Antibiotic prophylaxis has been reported to prevent recurrent episodes for as long as it is continued, with UTI usually recurring as soon as it is suspended (2). When antibiotics are combined with drugs that inhibit bacterial adhesion it appears that the dose can be reduced and recurrences are not as frequent.

The present study demonstrates that long-term results are better with a drop in the number of recurrences after prophylaxis was suspended.

\section{Conclusions}

Our study demonstrated that in female patients affected by recurrent UTI, the association between antibiotic prophylaxis and Cistimev ${ }^{\circledR}$ reduced the number of UTI in the
12 months following the end of prophylaxis and obtained a longer relapsing time, greatly improving the quality of life of the patients.

\section{REFERENCES}

1. Naber KG, Bergman B, Bishop MC, at all. EAU guidelines for the management of urinary and male genital tract infections. Urinary Tract Infection (UTI) Working Group of the Health Care Office (HCO) of the European Association of Urology (EAU); Urinary Tract Infection (UTI) Working Group of the Health Care Office (HCO) of the European Association of Urology (EAU). Eur Urol. 2001; 40:576-88.

2. Costantini E, Salvini E, Lazzeri $M$, et al. Prulifloxacin vs Phosphomycin: Prophylaxis in patients with recurrent UTI. Preliminary results of a randomized multi-centre study. Eur Urol 2011; (Suppl 10):480.

\section{Correspondence}

Emanuela Frumenzio, MD (Corresponding Author) emanuela.frumenzio@virgilio.it

Daniele Maglia, MD

Eleonora Salvini, $M D$

Silvia Giovannozzi, MD

Manuel Di Biase, MD

Vittorio Bini, MD

Elisabetta Costantini, MD

Clinica Urologica e Andrologica di Perugia,

Università degli Studi di Perugia, Perugia, Italy 